\title{
Effects of polyethyleneimine adsorption on rheology of bentonite suspensions
}

\author{
A ALEMDAR, N ÖZTEKIN ${ }^{\dagger}$, F B ERIM ${ }^{\dagger}$, Ö I ECE Ė $^{\dagger \dagger}$ and N GÜNGÖR* \\ Department of Physics, 'Department of Chemistry, ${ }^{\dagger}$ Department of Geology, Istanbul Technical University, 34469, \\ Maslak, Istanbul, Turkey
}

MS received 14 September 2004; revised 14 March 2005

\begin{abstract}
The influence of the cationic polymer, polyethyleneimine polymer (PEI) on the flow behaviour of bentonite suspensions $(2 \%, w / w)$, was studied. XRD, zeta potential and adsorption studies were done together with rheological measurements. The addition of PEI at concentration ranges of $10^{-5}-4.5 \mathrm{~g} / \mathrm{l}$ and their rheological properties and stability of bentonite suspensions were studied. The adsorption rates for the bentonite suspensions are very fast. The XRD results showed that the PEG molecules did not intercalate into the layers of the clay.
\end{abstract}

Keywords. Bentonite; polyethyleneimine; cationic polymer; rheology; zeta potential.

\section{Introduction}

Bentonites are clays containing mainly montmorillonites with minor amounts of non-clay minerals such as quartz, calcite, dolomite and feldspars. Montmorillonite is a member of the smectite group of clay minerals with the formal chemical composition $\left(\mathrm{Al}_{3 \cdot 15} \mathrm{Mg}_{0.85}\right)\left(\mathrm{Si}_{8 \cdot 00}\right) \mathrm{O}_{20}(\mathrm{OH})_{4}$ $\mathrm{X}^{+}{ }_{0.85} \cdot n \mathrm{H}_{2} \mathrm{O}$. Montmorillonite's atomic structure consists of an octahedral alumina sheet sandwiched between two tetrahedral silica sheets. In the tetrahedral sheets, tetravalent $\mathrm{Si}$ is sometimes replaced by trivalent $\mathrm{Al}$, whereas in the octahedral sheet, there may be substitutions of $\mathrm{Al}$ by $\mathrm{Fe}$ or $\mathrm{Mg}$. This isomorphic substitution may create excess of negative charges, which are compensated by the adsorption of interlayer cations. These exchangeables may determine many characteristic properties of montmorillonitic clays (Grim 1968; Olphen 1977; Hunter 1986).

The rheological parameters (viscosity, shear stress, yield value) of clay suspensions may often reflect particleparticle interactions. The magnitude of the attractive and repulsive forces between clay particles is determined by physical and chemical properties of the bentonite-water systems. As a result of these interactions, edge-to-edge (EE), edge-to-face (EF) and face-to-face (FF) attached clay particles may be observed by TEM studies (Vali and Bachmann 1988).

The polymers in the bentonite suspensions interact with clay particles according to their ionic or non-ionic character. The ionic polymers induce electrostatic interactions, but the non-ionic polymers are adsorbed on the surface of clay minerals by the steric interactions. Poly-

*Author for correspondence (nurfer@itu.edu.tr) mer concentration, its molecular weight and hydrolysis groups of polymer, size and shape of clay particle, its surface charge, clay concentration in suspension, $\mathrm{pH}$, and temperature may all affect the clay/polymer interactions.

The effects of salts, polymers and surfactant materials on the bentonite-water systems are extensively studied (Parfitt and Greenland 1970; Tadros 1987; Brandenburg and Lagaly 1988; Angle and Hamza 1989; Lagaly 1989; Billingham and Breen Yarward 1997; Ece et al 1999; Luckham and Rossi 1999; Güngör 2000; Öztekin et al 2002).

The use of polymers to control the stability of clay dispersions and their flocculation, is of great technological importance. The adsorption of polymers onto the surfaces of clay particles influence the rheology and stability of the system. Bentonites are used in a wide range of industrial processes such as paints, coatings, ceramics, pesticides, pharmaceuticals, cosmetics, cement, and drilling fluids. On the other hand, clays are much less expensive compared to common adsorbants like activated carbon. Clay can also remove unbiodegradable polymers from waste waters.

Adsorption of polymers onto clay particles has been extensively investigated, but papers on polyelectrolyte/ clay interactions are rare. Polyethyleneimine (PEI) is a cationic polymer and frequently used as a stabilizer of industrial suspensions. The adsorption of PEI on $\mathrm{SiO}_{2}$, $\mathrm{SiC}$ (Baklouti et al 1997), $\mathrm{Fe}_{2} \mathrm{O}_{3}$ (Radeva and Petkanchin 1997), and $\mathrm{ZrO}_{2}$ (Wang and Gao 1999) particles, were investigated. However, no report has been made about the adsorption interaction between PEI and smectites. We began to investigate PEI effect on bentonites of different areas in Turkey (Öztekin et al 2002). 
In the present paper, we have investigated as a function of PEI polymer concentration the rheological and electrokinetic properties of Ca-bentonite dispersions. The basal spacings of the $\mathrm{PEI} /$ bentonite compounds were studied by $\mathrm{X}$-ray diffraction.

\section{Experimental}

The clay sample was obtained from the bentonite deposits in Balikesir, Turkey (Marmara Konkurt Corp.). Ore samples were identified as Ca-bentonite by XRD analysis. XRD analyses were done using a Philips PW1140 model X-ray diffractometer. XRD data indicate the presence of a smectite (probably montmorillonite) with minor amount of impurities such as quartz, feldspar. This bentonite is mainly used in cat sand and detergent industries, but it can also be used in drilling mud after soda activation.

The chemical composition of the sample was determined by atomic absorption spectroscopy (Perkin Elmer 3030 model) except for silica, which was determined gravimetrically. The sample had the chemical composition (wt \%): $\mathrm{SiO}_{2}$ 62.73, $\mathrm{Al}_{2} \mathrm{O}_{3}$ 18.66, $\mathrm{Fe}_{2} \mathrm{O}_{3} 4 \cdot 60, \mathrm{CaO}$ 4.76, $\mathrm{MnO} 2 \cdot 35, \mathrm{Na}_{2} \mathrm{O} 1.33, \mathrm{~K}_{2} \mathrm{O} 2.57$ and $\mathrm{TiO}_{2} 0.76$. PEI (molecular mass range, $6 \cdot 10^{5}-1 \cdot 10^{6}$ ) was purchased from Fluka AG (Buchs, Switzerland). All other reagents were of analytical grade. All solutions were prepared with distilled water purified in an Elgacan C114 filtration system. All experiments were performed in polyethylene bottles to prevent the adsorption of PEI on the wall of glass containers.

Zeta potential measurements were carried out using Photal, CSA-600 model (Otsuka Electrokinetic Co.) microelectrophoresis instrument equipment with a microprocessor. A UV-Vis spectrophotometer (Jasco V530 model) was used to measure PEI concentrations of solutions at $200 \mathrm{~nm}$. A calibration curve was used between the concentration range 10 and $120 \mathrm{mg} / \mathrm{L}$ PEI.

The rheological parameters of the dispersions were measured in a Brookfield DVIII type low-shear viscometer in laboratory conditions. The bentonite was dispersed in water $(2 \%, \mathrm{w} / \mathrm{w})$ and shaken for $24 \mathrm{~h}$ before rheological measurements. An adsorption time of $24 \mathrm{~h}$ was adopted for the PEI. Once the curve of shear stress $(\tau)$ vs shear rate $(\gamma)$ was obtained for any clay under the given experimental conditions, the value of the extrapolated linear shear stress $\left(\tau_{\mathrm{y}}\right)$ was determined from the intersection of the extrapolated linear portion of the curve with the $\tau$-axis. The least squares method was used to determine the value of this intersection. The suspensions of the sample exhibit Bingham plastic behaviour. Pseudoplastic rheology of colloid suspensions may be described by the Bingham model (Güven 1992). At low shear rates, systems exhibit non-Newtonian flow, which is characterized by a progressive decline in viscosity as shear rate increases. Above a certain value of shear rate, the flow curve becomes linear. According to the Bingham model, the slope of the linear part of the flow curve is referred to as the plastic viscosity, the intercept of the linear portion of the curve with the stress axis is referred to as the Bingham yield (stress) value.

Very little amount of clay sample was mixed with distilled water in $10 \mathrm{ml}$ container and left for about $30 \mathrm{~min}$ in the ultrasonic vibrator for best dispersion. Small container was taken immediately from vibrator and dropped little by little into the sample chamber of zeta potentiometer and special care was taken to avoid for the entrance of air bubbles into thin channels of the instrument. The best measurement can be obtained within a certain range of optimum clay concentrations, otherwise zeta potential measurements cannot be done adequately, if concentration is too thick or too diluted. In order to make reliable measurements, certain counts must be obtained in zeta potentiometer and the range of these counts must not be too small or too big, which depends on the concentration of the slurry. For this reason, clay concentration was continuously checked and kept at optimum range. The measured electrophoretic mobilities were automatically converted to zeta potentials using a built-in microprocessor.

The adsorption rates were obtained by two different experiments. In the first experiment, $0 \cdot 2 \mathrm{~g}$ of the clay was added into $200 \mathrm{ml}$ of $100 \mathrm{mg} / \mathrm{l}$ PEI containing solution. As the solution was stirred at a rate of $420 \mathrm{rpm}$, the aliquots of $5 \mathrm{ml}$ was taken at a certain interval $(1,3,5,10$, 20 , 30th min and $24 \mathrm{~h}$ ), filtered from a $0.45 \mu \mathrm{m}$ membrane filter and PEI concentration was determined by measuring the absorbance value of solutions. Apparent absorption rates of the clays were determined on graphic by plotting the measured PEI concentrations vs time. For the second experiment, $0.2 \mathrm{~g}$ of the clay was stirred previously in $190 \mathrm{ml}$ water. Then, $10 \mathrm{ml}$ of $2000 \mathrm{mg} / \mathrm{l} \mathrm{PEI}$ solution was added to this solution and stirred. The decreasing PEI concentration in solution was determined as mentioned above. The comparison of two results gives us the effects of swelling and dispersion on the adsorption rates.

Adsorption isotherms were obtained using the batchequilibrium technique. Experiments were carried out in duplicate using $0.05 \mathrm{~g}$ adsorbent in $50 \mathrm{ml}$ of PEI solutions ranging in concentration from 20 to $200 \mathrm{mg} / \mathrm{l}$. Solutions were shaken for $24 \mathrm{~h}$ at $25^{\circ} \mathrm{C}$, centrifuged at $7500 \mathrm{rpm}$ for $2 \mathrm{~h}$, and the decanted solutions were filtered from $0.45 \mu \mathrm{m}$ membrane filter. The adsorbed PEI was calculated from the difference between the initial (without adsorbent) and equilibrium concentrations.

\section{Results and discussion}

The effect of PEI on the rheological properties of bentonite was correlated with the data of adsorption and electrokinetics experiments on Balikesir bentonite samples. For this reason, the adsorption rates of particles were first 
determined. The Bingham yield values of dispersions with PEI concentrations were measured and adsorption capacity of clay was found. These data were interpreted together with electrophoretic mobility measurements of suspensions.

The adsorption rate of the bentonite suspensions was easily found. It reached the equilibrium condition after about $5 \mathrm{~min}$. Apparent adsorption rates including the swelling and dispersion rates of clays are given in figure 1 . The dot lines in figure 1 show adsorption rates obtained after swelling of clays in water. There was no distinct difference between apparent and true adsorption rates, and hence swelling of clays does not affect the adsorption rates.

Figure 2 shows the change of Bingham yield value with PEI concentration in solution whereas figure 3 illustrates the adsorbed amount of PEI on clay particles ( $g$ $\mathrm{PEI} / \mathrm{g}$ clay) with the PEI concentration in the suspensions. In order to correlate the plot in figure 2 with adsorption isotherm in figure 3, PEI/clay weight ratios of suspensions are given on top of figures 2 and 3. As seen in figure 2, the initial Bingham yield value of the suspension remains constant until the concentration reaches to $10^{-3} \mathrm{~g} / \mathrm{l}$ PEI. A further increase is attributed to particle surface charge neutralization of clay with the adsorption of positively charged PEI and also bridging effect of PEI between clay particles in low PEI concentrations. Maximum point was $42 \%$ of adsorption capacity in the bentonite suspensions. Further increase in PEI concentration led to a decrease in the flocculation of dispersion probably due to the repulsions between positive charges on the clay surface at higher PEI concentrations, which prevent coagulation.

The adsorption isotherm in figure 3 shows a high affinity type that is characterized by a plateau after an initial sharp increase in adsorption values. The saturation level

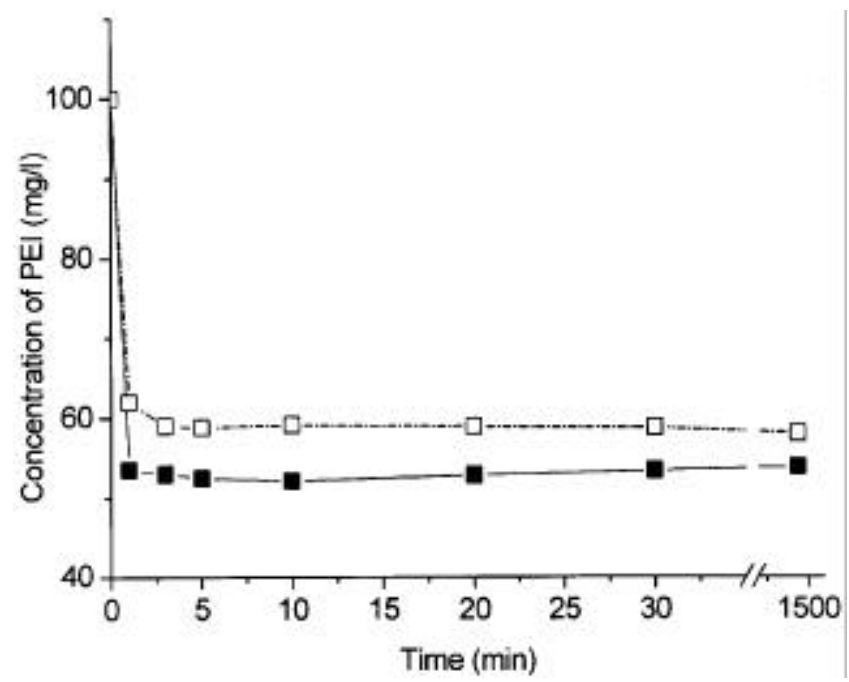

Figure 1. Concentration change of PEI in suspension vs time. The dot line gives adsorption rates obtained from pre-swelled clay in water. of the adsorption value for Balikesir bentonite was determined as $0.105 \mathrm{~g} \mathrm{PEI} / \mathrm{g}$ clay, which corresponds to $42 \%$ of the total amount of PEI added to the clay suspensions. The essentially linear adsorption curves of logarithm of the equilibrium concentration of PEI vs the adsorbed amount of $\mathrm{g}$ PEI/g clay fitted satisfactorily to the Freundlich adsorption equation with 0.992 regression (Öztekin et al 2002).

High adsorption rates indicate strong electrostatic interaction between clay particles and PEI, which is a cationic polymer. The imine groups on the chain are protonated and macromolecule gains a net positive charge, depending on the $\mathrm{pH}$ of the solution. Erim et al (1995) reported the use of this polymer as coating agent for silica capillaries. The electro-osmotic flow in the capillaries showed

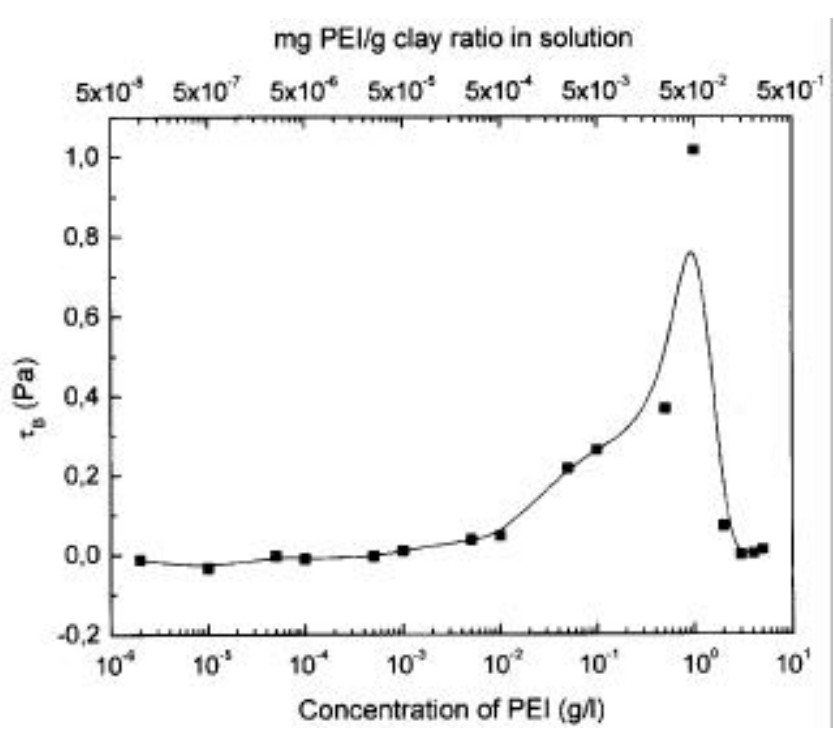

Figure 2. The influence of PEI on the Bingham yield value of $2 \%(\mathrm{w} / \mathrm{w})$ in the bentonite-water system.

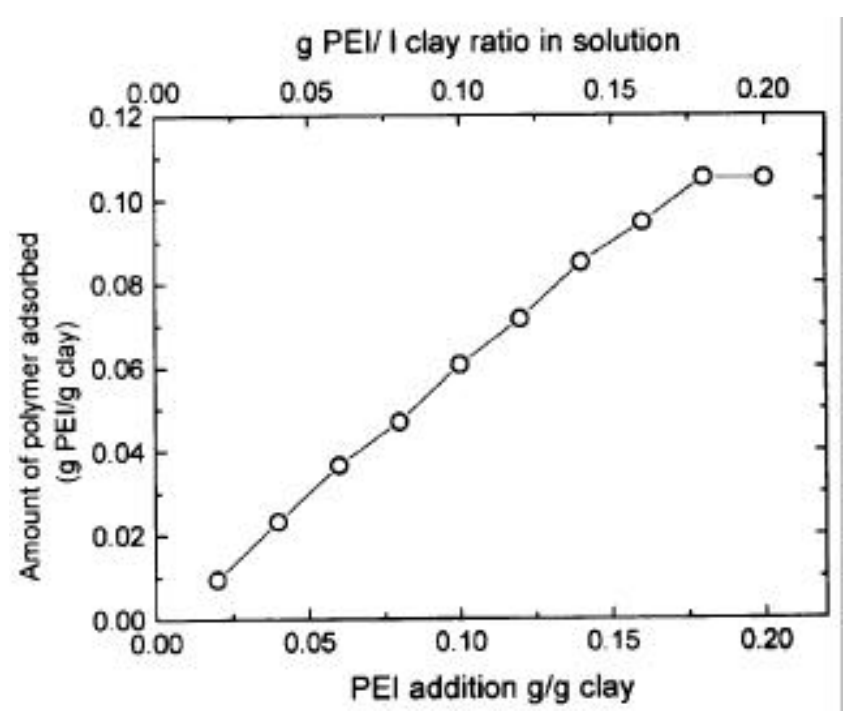

Figure 3. Adsorption isotherm of PEI on bentonite particles. 


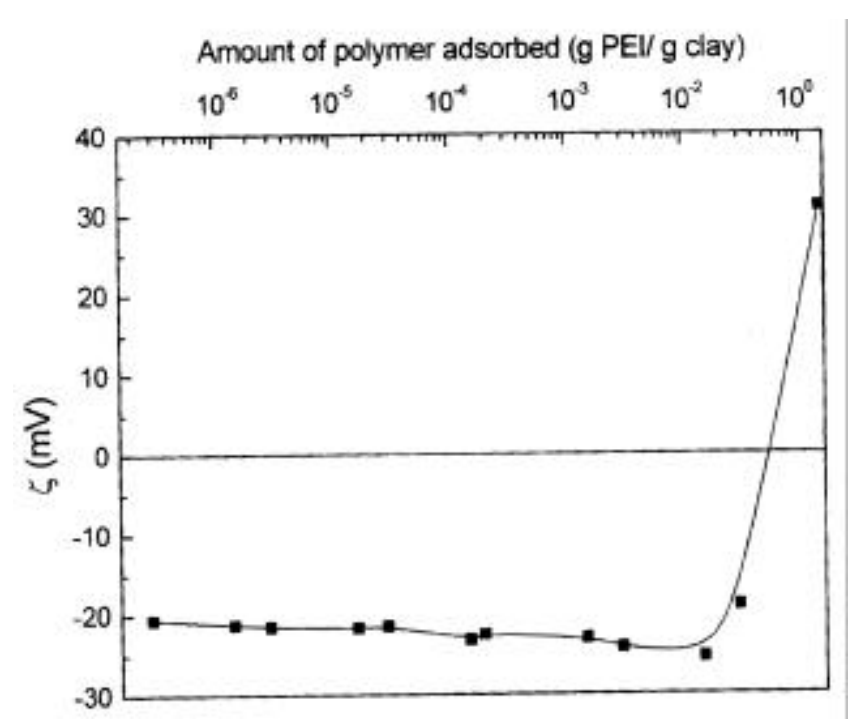

Figure 4. The zeta potential of Balikesir bentonite as a function of PEI concentration.

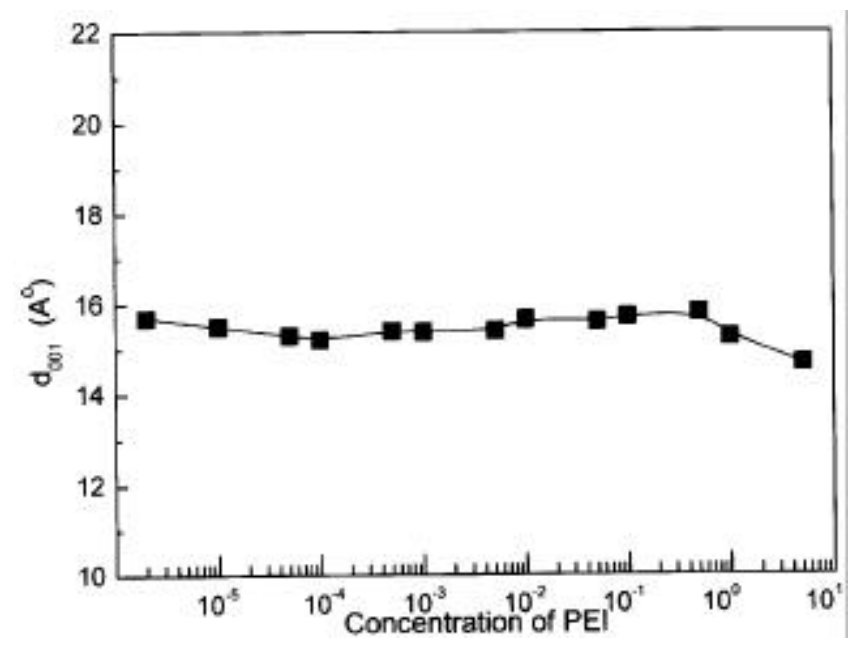

Figure 5. Variations in basal spacing $\left(d_{001}\right)$ in $\AA$ as a function of PEI concentration in the bentonite suspension.

that high molecular weight of PEI strictly depended on the $\mathrm{pH}$ of polymer solution and molecular weight of PEI that has a positive charge over a wide $\mathrm{pH}$ range between pH 3 and 11.

In the absence of PEI, the initial $\mathrm{pH}$ of the suspension was measured as $7 \cdot 8$. With the addition of PEI to the suspension, the $\mathrm{pH}$ values change between 8 and 8.4 . In this range of $\mathrm{pH}$, it is expected that both faces and edges of bentonite particles are negatively charged, whereas PEI has a net positive charge, so the driving force for adsorption should be electrostatic.

The zeta potential measurements of suspensions support this model, as seen in figure 4 that shows the change of zeta potential vs possibly adsorbed amount of PEI per
$1 \mathrm{~g}$ bentonite sample. In figure 4, as adsorbed amount increased, zeta potential reached zero point, which almost corresponds to the adsorption on maximum yield value point and with further adsorption zeta potential became a positive.

In order to understand whether added PEI can enter into the interlayer of clay minerals or not, XRD analyses were done to measure $d_{(001)}$ spacings. The interlayer distance ( $d$-space) of the clays was obtained from their characteristic peaks, based on Bragg's equation. Basal spacing $\left(d_{001}\right)$ of the smear slides are shown as a function of PEI concentration in figure 5. The study of $d=f(C)$ curves indicates that the BB-bentonite unit cell, $d_{(001)}$ spacing, did not increase and therefore, PEI molecules are not introduced in the interlayers of clay structure.

\section{Conclusions}

Rheological, electrokinetic parameters and XRD measurements have been widely used to characterize the claypolymer systems and are also used in this work.

The PEI molecules adsorbed strongly on the surface of the clay minerals. The adsorbed polyelectrolyte affects the rheological and electrokinetic properties of bentonite suspensions. Zero charge point obtained by measurement of zeta potential, the results of adsorption measurements (fast adsorption, etc) and changing behaviours of rheological parameters showed (i) the suspension flocculates by the addition of PEI up to a concentration of $1 \mathrm{~g} / \mathrm{l}$, (ii) the suspension deflocculates at about PEI concentration of $4.5 \mathrm{~g} / \mathrm{l}$. Thus, the degree of interaction between PEI and bentonite particles depends on the PEI concentration in the dispersion. The zeta potential measurements have shown that the PEI polymer stays on the clay particle and surfaces and the XRD studies have shown that they do not get into the basal intervals.

The effect of adsorption of PEI on bentonite clays collected from different regions of Turkey, Enez area, was investigated before (Öztekin et al 2002). Both Balikesir and Enez bentonites gave similar rheological and adsorption behaviours. The yield values at the maximum flocculation are 1.53 $\mathrm{Pa}$ and $1.02 \mathrm{~Pa}$ for Enez and Balikesir clays, respectively.

\section{Acknowledgements}

We would like to express our deepest appreciation to Prof. Shigeo Hayashi, Akita University, Research Institute of Materials and Resources, Japan, for providing zeta potential meter measurements.

\section{References}

Angle C W and Hamza H A 1989 Appl. Clay Sci. 4263

Baklouti S C, Pagnoux T, Chartier J F and Baumard J 1997

Euro. Ceram. Soc. 171387 
Billingham J C and Breen Yarwood J 1997 Vibrat. Spectrosc. 1419

Brandenburg U and Lagaly G 1988 Clay Sci. 3263

Ece O I, Güngör N and Alemdar A 1999 J. Inclusion Phenomena and Macrocycle Chem. 33155

Erim F B, Cifuentes A, Poppe and Kraak H 1995 J. Chromatogr. A708 356

Güngör N 2000 J. Appl. Polym. Sci. 75107

Güven N CMS 1992 Workshop lectures, Clay Minerals Soc. Boulder, CO, USA

Grim R E 1968 Clay mineralogy (New York: McGraw-Hill)

Hunter R J 1986 Foundation of colloid science (New York: Clarendon Press)
Lagaly G 1989 Appl. Clay Sci. 4105

Luckham P F and Rossi S 1999 Adv. Colloid \& Interface Sci. 8243

Olphen H Van 1977 Clay colloid chemistry (New York: Wiley) Öztekin N, Alemdar A, Güngör N and Erim F B 2002 Mater. Letts 5573

Parfitt R L and Greenland D J 1970 Clay Miner. 8305

Radeva T and Petkanchin I 1997 J. Colloid Interface Sci. 19687

Vali H and Bachmann L 1988 J. Colloid \& Interface Sci. 126 278

Tadros Th F 1987 Solid/liquid dispersions (New York: Academic Press)

Wang J and Gao L 1999 J. Colloid \& Interface Sci. 216436 